\title{
Private health care coverage and increased risk of obstetric intervention
}

\author{
Jennifer E Lutomski ${ }^{1}{ }^{2 *}$, Michael Murphy ${ }^{1}$, Declan Devane ${ }^{3}$, Sarah Meaney ${ }^{1}$ and Richard A Greene ${ }^{1}$
}

\begin{abstract}
Background: When clinically indicated, common obstetric interventions can greatly improve maternal and neonatal outcomes. However, variation in intervention rates suggests that obstetric practice may not be solely driven by case criteria.

Methods: Differences in obstetric intervention rates by private and public status in Ireland were examined using nationally representative hospital discharge data. A retrospective cohort study was performed on childbirth hospitalisations occurring between 2005 and 2010. Multivariate logistic regression analysis with correction for the relative risk was conducted to determine the risk of obstetric intervention (caesarean delivery, operative vaginal delivery, induction of labour or episiotomy) by private or public status while adjusting for obstetric risk factors.

Results: 403,642 childbirth hospitalisations were reviewed; approximately one-third of maternities (30.2\%) were booked privately. After controlling for relevant obstetric risk factors, women with private coverage were more likely to have an elective caesarean delivery (RR: 1.48; 95\% Cl: 1.45-1.51), an emergency caesarean delivery (RR: 1.13; 95\% Cl: 1.12-1.16) and an operative vaginal delivery (RR: 1.25; $95 \%$ Cl: 1.22-1.27). Compared to women with public coverage who had a vaginal delivery, women with private coverage were $40 \%$ more likely to have an episiotomy (RR: $1.40 ;$; $95 \%$ Cl: 1.38-1.43).

Conclusions: Irrespective of obstetric risk factors, women who opted for private maternity care were significantly more likely to have an obstetric intervention. To better understand both clinical and non-clinical dynamics, future studies of examining health care coverage status and obstetric intervention would ideally apply mixed-method techniques.
\end{abstract}

Keywords: Caesarean section, Vacuum extraction, Obstetric forceps, Induction of labour, Episiotomy, Pregnancy

\section{Background}

When clinically indicated, common obstetric interventions, such as caesarean delivery, operative vaginal delivery (i.e. vacuum or forceps extraction), induction of labour and episiotomy, can greatly improve maternal and neonatal outcomes. However, variation in intervention rates by socioeconomic indicators, such as type of health care coverage, suggests that obstetric practice may not be solely driven by case criteria. Disparities in caesarean delivery rates between women with public versus private health care coverage have been well

\footnotetext{
* Correspondence: J.Lutomski@ucc.ie

'National Perinatal Epidemiology Centre, Cork University Maternity Hospital, Wilton, Cork, Ireland

${ }^{2}$ Nijmegen Centre for Evidence Based Practice, Radboud University Medical Centre, Nijmegen, Netherlands

Full list of author information is available at the end of the article
}

reported in the United States [1-3], Australia [4,5], China [6], Europe [7-9] and Latin America [10,11]. Differences in incidence rates of operative vaginal delivery, induction of labour and episiotomy have also been observed $[4,5,12]$.

Thus, we explored the association between private maternity coverage and obstetric intervention in Ireland, a small country ( $\sim 4$ million residents) which offers universal maternity benefits to the 75,000 women who deliver each year in its jurisdiction. The current Irish model of maternity care was originally devised under the 1954 Maternity and Infant Care Scheme, which granted women ordinarily resident in Ireland access to free maternity services throughout pregnancy and up to six weeks postpartum [13]. Maternity care is jointly supervised between a general practitioner and a maternity health care provider.

\section{Biomed Central}


Under the public scheme, a woman may be seen by several different obstetricians and/or midwives throughout her pregnancy; low risk, non-operative vaginal deliveries are largely assisted by midwives. For an additional fee, women may opt for private maternity care, and in this case, care is alternated between a general practitioner and a consultant obstetrician, who will attend the delivery. Women may choose the consultant, or if a preference is not stated, a consultant obstetrician will be assigned. There are 20 maternity units across Ireland, of which 19 are public and one is private; private maternity care can be received at any of the public hospitals.

With this backdrop, the aim of our study was to complement current research in this area by comparing rates of obstetric intervention among women with private versus public health care coverage in the Irish maternity system. While allowing for case-mix variation, we examined differences in rates of elective caesarean and emergency delivery, operative vaginal delivery, induction of labour and episiotomy. We hypothesised, based on the previous literature, that obstetric interventions would be higher among women with private coverage.

\section{Methods}

We performed a population-based retrospective cohort study of deliveries occurring in Irish maternity units between January 1, 2005 and December 31, 2010. Data were extracted from the Hospital In-Patient Enquiry (HIPE) database [14], which provides nationally representative morbidity data coded according to the International Statistical Classification of Diseases and Related Health Problems, Tenth Revision, Australian Modification (ICD10-AM). For every hospital discharge, centrally trained personnel input basic demographics and up 20 diagnoses and/or procedures into identical, standardised data entry forms. These forms are subsequently submitted to the Economic and Social Research Institute, which is the national body responsible for data maintenance and dissemination of hospital activity [14]. In adherence with the Institute's protocol, HIPE data routinely undergo more than 140 validation checks, and since 2001, 18 chartbased audits have been performed [15-17]. The HIPE clinical coder training program and audit procedures have been independently assessed and were found to be accurate and reliable [15-17]. All 19 public maternity units submit data to HIPE. Thus, given the small obstetric volume of the single private maternity unit in the country $(<2,000$ deliveries per annum) and the low national home birth rate $(<1 \%)$, the HIPE database represents approximately $97 \%$ of all deliveries [18].

Childbirth hospitalisations were identified using the ICD-10-AM outcome of delivery code, Z37, which indicates the number of gestations (e.g. singleton, twin, or higher multiple order birth) and birth status (e.g. livebirth or stillbirth).

ICD-10-AM procedural codes were used to identify interventions of interest, which included: elective caesarean delivery (16520-00; 16520-02), emergency caesarean delivery $(16520-01 ; 16520-03)$, vacuum extraction $(90469-00)$, forceps extraction (90468-00/01/02/03/04; 90470-02/04), medical and surgical induction of labour (90465-00/01/02/ 03/04/05), and episiotomy (90472-00). In the Irish context, caesarean deliveries coded as elective refer to a caesarean delivery which occurs prior to labour. Failed attempts at vacuum and forceps extraction (90469-01; 90468-05) which resulted in caesarean delivery were not included in the overall rates of operative vaginal delivery. Records with no indication of caesarean delivery or vacuum/forceps extraction were presumed to be non-operative vaginal deliveries. We also identified epidural/spinal anaesthesia usage (92506-sub-divisions; 92507-sub-divisions; 92508sub-divisions; 92516-00), as this procedure is known to be associated with operative vaginal delivery.

From ICD-10-AM diagnostic codes, we identified potential confounders as maternal morbidities and deliveryrelated factors which are associated with increased risk of obstetric intervention. Given the wide spectrum of morbidities which may affect an individual pregnancy and childbirth, we decided a priori to focus on three primary conditions which are frequently diagnosed in pregnancy and are likely to impact on the decision for obstetrical intervention: heart disease, diabetes and placental disorders. These morbidities were clinician-defined according to local hospital policy. We classified heart disease as diagnosis of chronic rheumatic heart disease (I05-I09), ischemic heart disease (I25), pre-existing hypertensive diseases (I10-I13; I15; I27; O10), gestational-induced hypertensive diseases (O13; O14; O15), and cases of hypertension where onset was unspecified (O11; O16). Similarly, we created a composite category for diabetes, which included diagnosis of established diabetes (E10-14; O24.0,1,2,3), gestational-induced diabetes (O24.4), and cases where onset was unspecified (O24.9). Placental disorders included placental malformations $(\mathrm{O} 43.1,2,8,9)$, placenta praevia (O44) and placental abruption (O45). Other common obstetric risk factors included previous caesarean delivery (O34.2; O75.7) and multiple birth (Z37.2,3,4,5,6,7).

For the descriptive analysis, the overall mode of delivery rate by health care coverage status was reported per 100 deliveries. We examined six-year trends in private health care coverage and mode of delivery by health care coverage status using Cochrane-Armitage tests for trend. Multivariate logistic regression analyses were conducted to examine the association between health care coverage status and (1) elective caesarean delivery; (2) emergency caesarean delivery; (3) operative vaginal delivery (vacuum, forceps extraction); (4) induction of labour 
(use of prostaglandins, oxytocin, artificial rupture of membrane and other medical/surgical interventions); and (5) episiotomy. Given the frequency of our outcomes of interest ( $>10 \%)$, adjusted odds ratios were corrected to estimate the corresponding relative risks [19]. Thus, throughout this manuscript, estimates are described in terms of risk rather than odds.

In the multivariate models, adjustment for confounders varied by the risk associated with the outcome of interest. For induction of labour [20], adjustments were made for age, heart disease, diabetes, placental disorders and previous caesarean delivery. For elective and emergency caesarean delivery, adjustments were made for age, heart disease, diabetes, placental disorders, previous caesarean delivery and multiple birth. In light of recent evidence, epidural anaesthesia [21] and induction of labour [22] were not considered as confounders for caesarean delivery. For operative vaginal deliveries, adjustments were made for age, heart disease, diabetes, previous caesarean delivery, multiple birth, induction of labour and epidural. The interaction term between induction of labour and epidural was also included in the model. Lastly, for episiotomy, adjustments were made for age, multiple birth and operative vaginal delivery.

Similar to previous work [23], in order to construct the most appropriate comparison groups for our outcomes of interest, consideration was given to the intrinsic hierarchy of delivery pathways. Since all pregnancies are theoretically "at risk" for elective caesarean delivery (i.e. a pre-labour caesarean delivery), in the first model, we compared the likelihood of elective caesarean delivery versus all other modes of delivery. However, only women who undertake a trial of labour are at risk for emergency caesarean delivery, operative vaginal delivery and induction of labour. Thus, in the subsequent models assessing these interventions, we excluded elective caesarean deliveries $(n=48,214)$. Specifically, the likelihood of emergency caesarean delivery was compared to vaginal deliveries (both operative and non-operative), and the likelihood of operative vaginal delivery was compared to emergency caesarean/non-operative vaginal delivery. Induction of labour was examined among women with an emergency caesarean or vaginal delivery. Lastly, only women with a vaginal delivery are at risk for episiotomy; therefore in our final model, we excluded both elective and emergency caesarean deliveries $(n=103,045)$, and compared the likelihood of episiotomy among women with an operative or non-operative vaginal delivery. Analyses were conducted using SAS V9.3 (SAS Institute Inc., Carey, NC, USA).

\section{Ethics statement}

This study was exempt from institutional board review as hospital discharge records do not contain unique identifiers and are available for public access (University College Cork Clinical Research Ethics Committee, Ref. No. ECM4(g)05/08/08).

\section{Results}

403,642 childbirth hospitalizations were reviewed. Over the six-year period, approximately one-third of maternities (30.2\%) were booked privately. The percentage of private bookings steadily decreased over the study period, from $33.3 \%$ to $24.2 \%$ (results not shown; test for trend $p$-value $<0.001)$.

In the overall cohort, mode of delivery distribution differed by health care coverage status (Table 1). Women with private coverage were almost twice as likely to have an elective caesarean delivery (17.8\% versus $9.4 \%)$. However, the emergency caesarean rate was similar between women with private and public coverage (14.3\% versus $13.3 \%$ respectively), and only minor differences in the rates of operative vaginal delivery were observed.

Nonetheless, there were underlying differences in casemix between women with private and public coverage. Whereas more than three-quarters of women with private coverage were between 30 and 39 years old (78.9\%), less than half of women with public coverage (45.8\%) fell within this age bracket. No major differences in rates of heart disease or placental disorders were observed; though, reported rates of diabetes (established or gestational-induced) were modestly lower among women with private coverage. Among women with private coverage who undertook a trial of labour, all forms of induction of labour were higher, as was use of epidural anaesthesia. Furthermore, episiotomy rates for vaginal deliveries were substantially higher among women with private coverage. The rate of previous caesarean delivery among women with private coverage was nearly double that observed among women with public coverage; multiple gestations were also more frequent in women with private coverage.

Changing patterns in obstetric intervention were evident between 2005 and 2010. Increasing caesarean delivery rates were more pronounced among women with private coverage $(30.2 \%$ to $34.7 \%)$ than women with public coverage $(22.2 \%$ to $23.8 \%)$ (test for trend $\mathrm{p}$-value $<0.0001$; Figure 1, Panel A). The increasing caesarean rate in women with private coverage was predominately driven by an increase in elective caesarean deliveries (Figure 1, Panel B). Notably, there was a concurrent decrease in attempted trial of labour after previous caesarean (results not shown). Whereas rates of vacuum (test for trend $\mathrm{p}$-value $=0.14$ ) and forceps extraction (test for trend $\mathrm{p}$-value $=0.32$ ) were stable among women with private coverage who underwent labour, significant increasing trends in operative vaginal delivery were observed among women with public coverage (test for trend 
Table 1 Distribution of maternal and obstetric characteristics for public and private deliveries, Ireland, 2005-2010

\begin{tabular}{|c|c|c|}
\hline & $\begin{array}{l}\text { Private deliveries } \\
\qquad(\mathrm{N}=122,072)\end{array}$ & $\begin{array}{c}\text { Public deliveries } \\
(\mathrm{N}=\mathbf{2 8 1}, \mathbf{5 7 0})\end{array}$ \\
\hline \multicolumn{3}{|l|}{ Maternal characteristics } \\
\hline \multicolumn{3}{|l|}{ Age (years) } \\
\hline$<20$ & $0.2(286)$ & $4.8(13,585)$ \\
\hline $20-29$ & $13.9(17,006)$ & $46.3(130,292)$ \\
\hline $30-39$ & $78.9(96,298)$ & $45.8(128,831)$ \\
\hline$\geq 40$ & $7.0(8,482)$ & $3.2(8,862)$ \\
\hline \multicolumn{3}{|l|}{ Morbidity } \\
\hline Heart disease ${ }^{a}$ & $5.5(6,732)$ & $5.4(15,251)$ \\
\hline Diabetes mellitus ${ }^{\mathrm{b}}$ & $1.4(1,761)$ & $2.3(6,446)$ \\
\hline Placental disorders ${ }^{c}$ & $1.2(1,476)$ & $1.1(3,110)$ \\
\hline \multicolumn{3}{|l|}{ Mode of delivery } \\
\hline Caesarean, elective & $17.8(21,667)$ & $9.4(26,547)$ \\
\hline Caesarean, emergency & $14.3(17,428)$ & $13.3(37,403)$ \\
\hline Vaginal, operative, total ${ }^{d}$ & $18.1(22,069)$ & $14.9(41,995)$ \\
\hline Vacuum & $13.2(16,076)$ & $11.5(32,302)$ \\
\hline Forceps & $4.7(5,734)$ & $3.3(9,256)$ \\
\hline Combined & $0.2(259)$ & $0.2(437)$ \\
\hline Vaginal, non-operative & $49.9(60,908)$ & $62.4(175,625)$ \\
\hline \multicolumn{3}{|l|}{ Induction of labour ${ }^{\mathrm{e}}$} \\
\hline Prostaglandin & $7.0(6,986)$ & $6.0(15,273)$ \\
\hline Oxytocin & $3.7(3,723)$ & $3.5(8,901)$ \\
\hline Artificial rupture of membrane & $6.1(6,091)$ & $4.7(12,054)$ \\
\hline Other $r^{f}$ & $16.4(16,457)$ & $12.1(30,747)$ \\
\hline Total induction & $32.5(32,622)$ & $26.0(66,320)$ \\
\hline \multicolumn{3}{|l|}{ Select procedures } \\
\hline Episiotomy ${ }^{9}$ & $29.5(24,500)$ & $20.9(45,575)$ \\
\hline Epidural usage $\mathrm{e}^{\mathrm{e}}$ & $64.1(64,386)$ & $50.4(128,516)$ \\
\hline \multicolumn{3}{|l|}{ Other obstetric conditions } \\
\hline Previous caesarean delivery & $15.1(18,487)$ & $8.7(24,454)$ \\
\hline Multiple birth & $2.2(2,693)$ & $1.4(4,039)$ \\
\hline
\end{tabular}

Note: Rates are \% (N). Rates are based on all deliveries $(n=403,642)$ unless otherwise stated.

ancludes chronic rheumatic heart disease, ischemic heart disease and pre-existing/ gestational-induced hypertensive diseases.

${ }^{b}$ Includes pre-existing and gestational-induced diabetes.

'Includes placental malformations, placenta praevia and placental abruption.

${ }^{\mathrm{d} C}$ Categories are not mutually exclusive.

e Rates are based on emergency caesarean and vaginal (operative and nonoperative) deliveries only $(n=355,428)$.

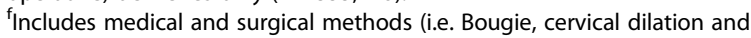
Foley's catheter) not elsewhere specified.

${ }^{9}$ Rates are based on vaginal deliveries only $(n=300,597)$.

p-values <0.0001; Figure 2, Panels A and B). Induction of labour rates were relatively stable in both groups of women (results not shown). In contrast, among women with a vaginal delivery, episiotomy rates significantly increased for both women with private (28.9\% to $31.3 \%$ ) and public coverage $(19.0 \%$ to $22.7 \%)$ (results not shown, test for trend p-value $<0.0001$ ).

In the univariate models, women with private coverage had increased risks of caesarean delivery, operative vaginal delivery, induction of labour, and episiotomy; adjustment in the multivariate models did not attenuate observed risks (Table 2). After controlling for relevant obstetric risk factors, women with private coverage were $48 \%$ more likely to have an elective caesarean delivery, 13\% more like to have an emergency caesarean delivery and 25\% more likely to have an operative vaginal delivery. Risk of forceps extraction was higher than risk of vacuum extraction. Risk of induction of labour varied by type; however overall, women with private coverage were $27 \%$ more likely to have an induction of labour relative to women with public coverage. Compared to women with public coverage with a vaginal delivery, women with private coverage were $40 \%$ more likely to have an episiotomy.

\section{Discussion}

Irrespective of obstetric risk factors, we found that women who opted for private maternity care in Ireland were significantly more likely to have an obstetric intervention than women who opted for public care. Although such disparities have not been found in all settings [24,25], our research contributes to a growing body of evidence which supports such an association [1-11]. Due to fundamental differences between study designs and operational definitions, risk estimates describing the impact of private health care coverage on obstetric intervention are not directly comparable. However, assessing the influence of health care coverage status in a variety of health care settings is critical given that rates of obstetric intervention are likely impacted by a country's prevailing model of obstetric care (i.e. midwifeled, obstetrician-led or shared care models) and health care system (i.e. socialised medicine or fee-for-service).

The variation in the overall caesarean rate between women with public and private coverage is of concern, particularly given that increasing trends in elective caesarean delivery were disproportionately higher among women with private coverage. Although generally a safe procedure, caesarean delivery is a major abdominal surgery associated with increased postpartum recovery time, higher risk of uterine complications in future pregnancies, and increased risk of respiratory morbidities for the infant [26]. While undoubtedly such trends are impacted by differences in obstetric profiles, our study suggests that health care coverage status is likely an independent risk factor for caesarean delivery.

Yet, health care coverage status is part of a broad spectrum of non-clinical reasons, including obstetrician preference [27,28], litigation fears [29-31], maternal preference 

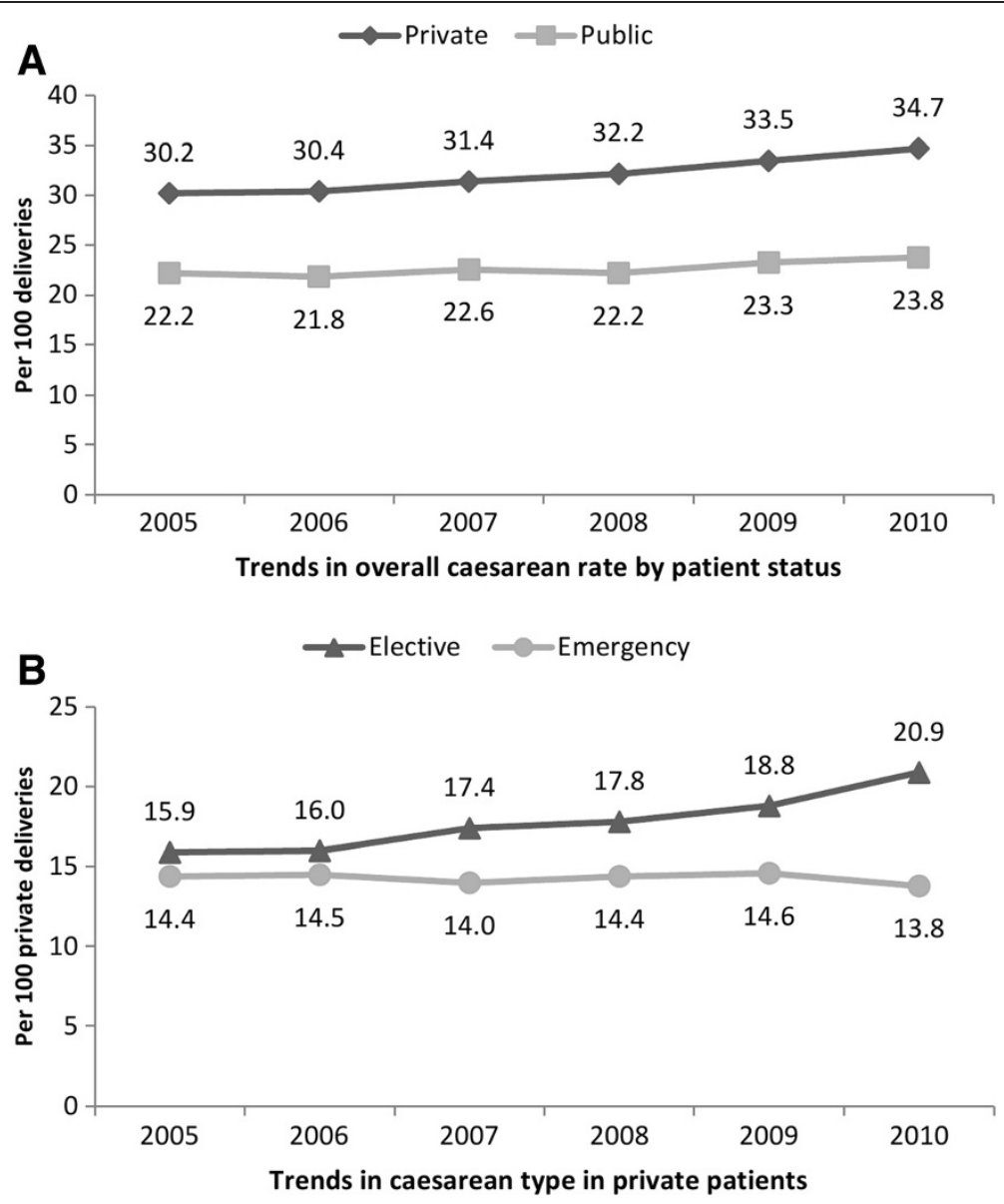

Figure 1 Trends in caesarean delivery by health care coverage status, Ireland, 2005-2010 (Panels A and B).

[32,33], and fewer women attempting a trial of labour after previous caesarean [34,35]. For this reason, to better understand both clinical and non-clinical dynamics, in future studies of health care coverage status and caesarean delivery, mixed-method research would be a clear advantage. Given the heterogeneity in obstetric risk factors among women who receive a caesarean delivery, the quantitative component of such an analysis may consider performing a more detailed and standardised classification of caesarean delivery, for example by applying the Robson 10-Group Criteria [36]. The Robson 10Group Criteria classify caesarean deliveries according to fetal position, number of gestations, parity, course of labour and gestational age, and thus this classification system inherently captures many important risk factors for obstetric intervention. Group-specific caesarean delivery rates can then be derived and compared between women at high and low risk for caesarean delivery. For example, whereas as higher rates of caesarean delivery can be expected among nulliparous breech pregnancies (Robson Group 6), lower rates would be expected among nulliparous, single cephalic, term pregnancies with spontaneous labour (Robson Group 1). Using this framework, qualitative research can be undertaken to investigate the different dynamics in different subgroups which present with varying levels of risk for caesarean delivery. Such research would ideally focus on clinical decision-making and the influence of the personal preferences of women versus maternity care professionals. We believe that this research design could greatly enhance our current understanding of the influence of private health care coverage on caesarean delivery.

Over the study period, we found a significant increase in the proportion of women with public coverage having an operative vaginal delivery; though interestingly, such trends were not observed among women with private coverage. In particular, the increase in forceps deliveries among women with public coverage was unexpected. Although increases in vacuum extraction have been reported in other settings, typically, this is coupled with a decrease in forceps extraction [5,37]. The increases we observed in operative vaginal delivery could potentially represent a more interventional practice style, or in contrast, a pro-active effort to avoid caesarean delivery. 

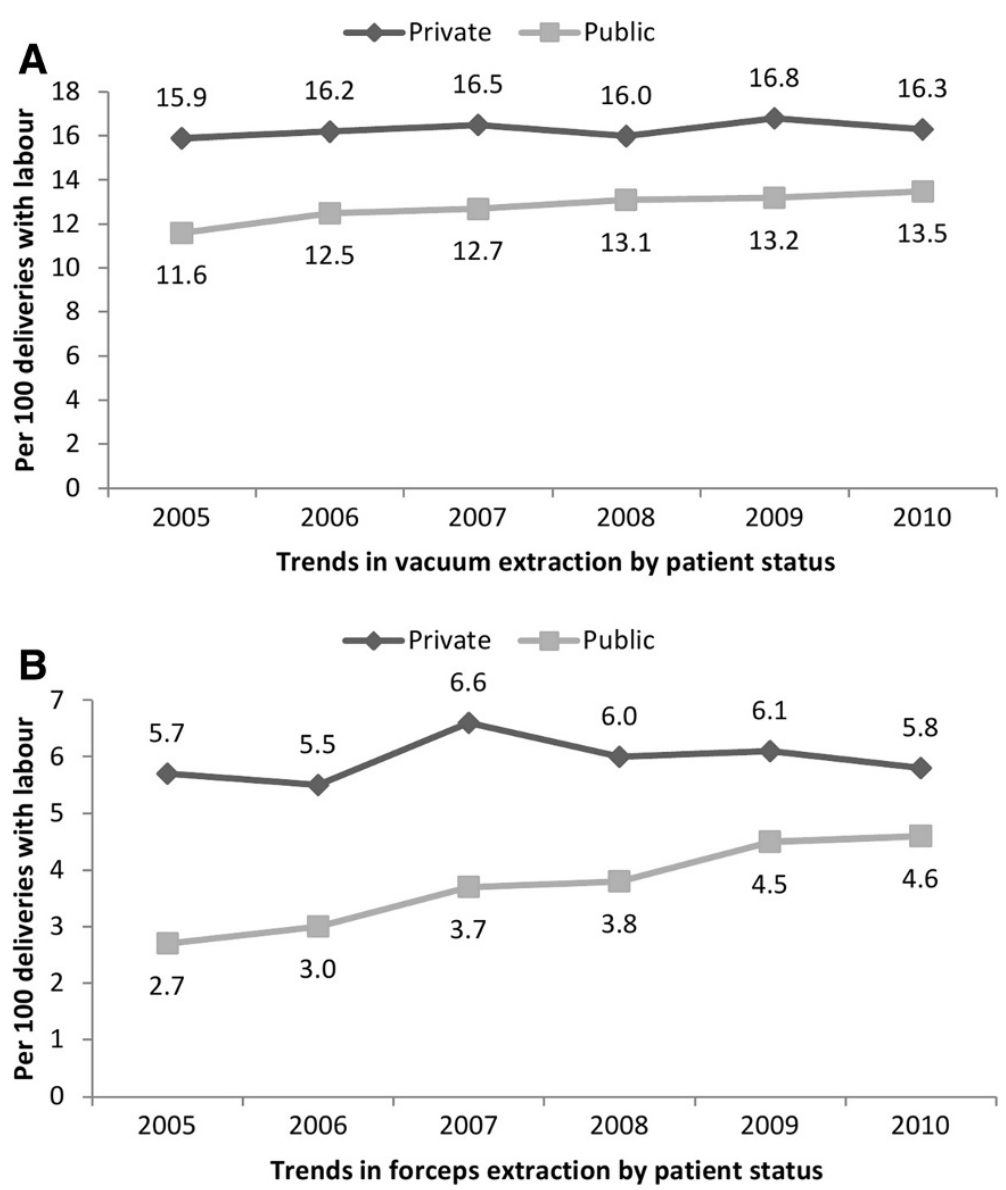

Figure 2 Trends in operative vaginal delivery by health care coverage status, Ireland, 2005-2010 (Panels A and B).

Similarly to caesarean delivery, operative vaginal delivery in and of itself is not without risk of increased maternal morbidity [38], and thus detailed clinical audit is warranted to further investigate observed patterns in women with public health care coverage.

We found that rates of episiotomy were significantly higher among women with private coverage, which is disconcerting given that liberal use of episiotomy may increase risk of severe perineal trauma, posterior perineal trauma, more extensive suturing and complications in healing [39]. In light of such evidence, major obstetrical societies have advocated restrictive use of episiotomy to decrease maternal morbidity [40,41]. Such guidelines have subsequently led to a decrease in rates over the past three decades $[42,43]$. We are unable to confirm why differences in episiotomy rates were observed in this population. Speculatively, however, uncomplicated deliveries in the public scheme are largely attended by midwives, who may be less likely to carry out an episiotomy [44].

Our study is subject to several biases. Firstly, residual confounding is of concern as we were not able to adjust for all maternal (e.g. parity, obesity, assisted conception, ethnicity and socio-economic status) and fetal (e.g. position, intrauterine growth restriction, macrosomia, heart rate) risks factors which may have increased risk of obstetric intervention. Given that HIPE is a minimal dataset with the primary objective of auditing overall clinical activity, these factors were not built into the original HIPE dataset. Parity in particular is a well-established risk factor for obstetric intervention, and previous reports from Ireland have shown that multiparous women are substantially less likely to have an operative vaginal delivery and slightly less likely to have a caesarean delivery [18]. If the distribution of parity (as well as other aforementioned factors unavailable in the HIPE dataset) differed by health care coverage status, estimates reported in this analysis may be biased. It is difficult, however, to speculate the directionality of such bias because certain risks may be higher in women with private coverage whereas other risks may be higher in women with public coverage. Notably, new variables continue to be introduced into the HIPE dataset, and commencing in 2012, information on parity will be available. However, to the authors' knowledge, there are no published studies to date 
Table 2 Unadjusted and adjusted relative risks for obstetric intervention in women with private versus public health care coverage, Ireland, 2005-2010

\begin{tabular}{|c|c|c|}
\hline & $\begin{array}{l}\text { Unadjusted } \\
\text { RR }(95 \% \mathrm{Cl})\end{array}$ & $\begin{array}{c}\text { Adjusted } \\
\text { RR }(95 \% \mathrm{Cl})\end{array}$ \\
\hline \multicolumn{3}{|l|}{ Induction of labour ${ }^{a}$} \\
\hline Total induction & $1.25(1.24-1.26)$ & $1.27(1.26-1.29)$ \\
\hline Prostaglandin & $1.16(1.13-1.19)$ & $1.18(1.14-1.20)$ \\
\hline Oxytocin & $1.06(1.02-1.10)$ & $1.10(1.05-1.13)$ \\
\hline Artificial rupture of membrane & $1.28(1.24-1.32)$ & $1.25(1.22-1.29)$ \\
\hline Other $^{\mathrm{b}}$ & $1.36(1.34-1.38)$ & $1.41(1.38-1.44)$ \\
\hline \multicolumn{3}{|l|}{ Mode of delivery } \\
\hline Elective caesarean ${ }^{c, d}$ & $1.88(1.85-1.91)$ & $1.48(1.45-1.51)$ \\
\hline Emergency caesarean $^{d}$ & $1.18(1.16-1.20)$ & $1.13(1.12-1.16)$ \\
\hline Vaginal, operative, total ${ }^{\mathrm{e}}$ & $1.33(1.32-1.35)$ & $1.25(1.22-1.27)$ \\
\hline Vacuum ${ }^{e}$ & $1.27(1.25-1.29)$ & $1.19(1.17-1.22)$ \\
\hline Forceps $^{\mathrm{e}}$ & $1.57(1.52-1.62)$ & $1.39(1.34-1.45)$ \\
\hline \multicolumn{3}{|l|}{ Select procedures } \\
\hline Episiotomy $^{f}$ & $1.41(1.39-1.43)$ & $1.40(1.38-1.43)$ \\
\hline
\end{tabular}

Note: All risk estimates are based on emergency caesarean or vaginal (operative and non-operative) deliveries $(n=355,428)$ unless otherwise stated. ${ }^{a}$ Adjusted for age, heart disease, diabetes, placental disorders, previous caesarean delivery.

${ }^{\mathrm{b}}$ Includes medical and surgical methods not elsewhere specified. 'Based on all deliveries $(n=403,642)$.

${ }^{\mathrm{d}}$ Adjusted for age, heart disease, diabetes, placental disorders, previous caesarean delivery and multiple birth.

${ }^{\mathrm{e}}$ Adjusted for age, heart disease, diabetes, previous caesarean delivery, multiple birth, induction of labour and epidural. The interaction term between induction of labour and epidural was also included in the model.

${ }^{\mathrm{f}}$ Based on vaginal deliveries only $(\mathrm{N}=300,597)$; adjusted for age, multiple birth and operative vaginal delivery.

that report nationally representative figures of parity by health care coverage status. Linking hospital discharge data with maternal/infant medical charts and birth registration forms is another mechanism to counter this limitation, though linked datasets are currently not in compliance with current health information regulations in Ireland.

Secondly, reporting bias is an issue when using secondary administrative datasets, such as the HIPE database. Data extracted from hospital records may underreport the true extent of covariates and outcomes of interest in this population. Nonetheless, validation studies performed in other countries have found that hospital discharge datasets [45], including those coded using the ICD-10-AM [46], are highly sensitive and specific for many obstetric conditions and interventions. These findings, coupled with the previous findings which have demonstrated the accuracy and reliability of the HIPE database [16,17], lend to the credibility of our results.

Thirdly, the HIPE database lacks unique maternal identifiers, and therefore we were unable to link deliveries for women who had multiple pregnancies over the study period. Such information would have facilitated a useful sub-analysis focusing on women who alternated between private and public care in different pregnancies or to examine clustering by the unit of the individual woman. Lacking a unique identifier further impacted the use of a multi-diagnostic/procedural definition to extract childbirth hospitalisations [47], as such a metric would have increased the risk of duplicate records (e.g. in the case of transfers) [48]. Moreover, since the type of caesarean delivery (elective versus emergency) is not independently recorded in the HIPE database, this method would have also prevented the examination of caesarean type by health care coverage status, which we deemed highly important in this analysis. Notably, the proportion of childbirth hospitalisations missed using an outcome of delivery code is relatively small [47], and previous reports from Ireland have shown a high degree of concordance between estimates based on birth records versus outcome of delivery codes from hospital discharge records $[18,49]$.

Lastly, we were unable to definitely discern if observed differences were a result of health care coverage status or the attending maternity care provider (i.e. obstetrician versus midwife). This is an important distinction that warrants further investigation. In our opinion, however, disparities in obstetric intervention are likely not attributed to solely one factor, but rather a confluence of factors. For this reason, we firmly advocate research which integrates the preferences of women and maternity care providers with clinical indications for intervention.

\section{Conclusions}

In conclusion, our review of recent data from Ireland demonstrates that significant differences in obstetric intervention in women with private and public health care coverage persist and are unlikely to be explained by differences in clinical risk factors alone. While there is clear value in decreasing unnecessary obstetric intervention, how to best achieve this aim will likely require reassessment of obstetric management at both the local and national level. The incorporation of targeted strategies, such as timely implementation of evidence-based guidelines, mandatory secondary opinion and detailed consultations may be of benefit [50]. Successful initiatives would likely require a multi-dimensional approach which addresses concerns held by both the mother and health care provider.

\section{Details of ethical approval}

This study was exempt from University College Cork Clinical Research Ethics Committee review as it used publicly available, anonymised data (Ref. No. ECM4(g) 05/08/08). 


\section{Competing interests}

The authors declare that they have no competing interests.

\section{Authors' contributions}

JEL, DD and MM contributed to the design and analysis of the study. JEL and $M M$ contributed to the drafting of the initial manuscript. JEL, DD, MM, SM and RAG contributed critical revision of the manuscript for intellectual content and approved its submission for publication. All authors read and approved the final manuscript.

\section{Acknowledgements}

We would like to acknowledge the Economic and Social Research Institute of Ireland for technical support and provision of the HIPE dataset.

\section{Funding}

This research was supported by the National Perinatal Epidemiology Centre of Ireland.

\section{Author details}

'National Perinatal Epidemiology Centre, Cork University Maternity Hospital, Wilton, Cork, Ireland. ${ }^{2}$ Nijmegen Centre for Evidence Based Practice, Radboud University Medical Centre, Nijmegen, Netherlands. ${ }^{3}$ School of Nursing and Midwifery, National University of Ireland, Galway, Ireland.

Received: 4 June 2013 Accepted: 24 December 2013

Published: 13 January 2014

\section{References}

1. Huesch MD: Association between type of health insurance and elective cesarean deliveries: New Jersey, 2004-2007. Am J Public Health 2011 101(11):e1-e7. 2011/11/01

2. Misra A: Impact of the health choice program on cesarean section and vaginal birth after $\mathrm{C}$-section deliveries: a retrospective analysis. Matern Child Health J 2008, 12(2):266-274

3. Lipkind HSDC, Rosenberg TJ, Funai EF, Chavkin W, Chiasson MA: Disparities in cesarean delivery rates and associated adverse neonatal outcomes in New York City hospitals. Obstet Gynecol 2009, 113(6):1239-1247.

4. Roberts $\mathrm{CL}$, Tracy S, Peat B: Rates for obstetric intervention among private and public patients in Australia: population based descriptive study. BMJ 2000, 321(7254):137-141.

5. Dahlen HG, Tracy S, Tracy M, Bisits A, Brown C, Thornton C: Rates of obstetric intervention among low-risk women giving birth in private and public hospitals in NSW: a population-based descriptive study. BMJ Open 2012, 2(5). doi: 10.1136/bmjopen-2012-001723.

6. Cai WW MJ, Chen $\mathrm{CH}$, Zhuang YX, Morris L, Harris JR: Increased cesarean section rates and emerging patterns of health insurance in Shanghai, China. Am J Public Health 1998, 88(5):777-780. 1998 May.

7. Mossialos EAS, Karras K, Davaki K: An investigation of Caesarean sections in three Greek hospitals: the impact of financial incentives and convenience. Eur J Public Health 2005, 15(3):288-295. Epub 2005 May 27.

8. Di Lallo D, Perucci CA, Bertollini R, Mallone S: Cesarean section rates by type of maternity unit and level of obstetric care: an area-based study in central Italy. Prev Med 1996, 25(2):178-185.

9. Coulm B, Le Ray C, Lelong N, Drewniak N, Zeitlin J, Blondel B: Obstetric interventions for low-risk pregnant women in France: do maternity unit characteristics make a difference? Birth 2012, 39(3):183-191.

10. Barros AJD, Santos IS, Matijasevich A, et al: Patterns of deliveries in a Brazilian birth cohort: almost universal cesarean sections for the better-off. Rev Saude Publica 2011, 45:635-643.

11. Murray SF: Relation between private health insurance and high rates of caesarean section in Chile: qualitative and quantitative study. BMJ 2000, 321(7275):1501-1505.

12. Roberts CL, Algert CS, Carnegie M, Peat B: Operative delivery during labour: trends and predictive factors. Paediatr Perinat Epidemiol 2002. 16(2):115-123

13. Kennedy P: Healthcare reform: maternity service provision in Ireland. Health Policy 2010, 97:145-151.

14. The economic and social research institute. Hospital in-patient enquiry scheme [online]. Available: http://www.esri.ie/health_information/hipe/. Accessed 29 July 2012
15. Lutomski JE, Morrison JJ, Greene RA, Lydon-Rochelle MT: Maternal morbidity during hospitalization for delivery. Obstet Gynecol 2011, 117(3):596-602.

16. Bramley $M$, Reid BA: Morbidity data quality initiatives in Ireland. HIM J 2005, 34(2):47-53.

17. Bramley $M$, Reid BA: Clinical coder training initiatives in Ireland. HIM J 2005, 34(2):40-46.

18. The Economic and Social Research Institute: National perinatal reporting system perinatal statistics report. 2010. Available: http://www.esri.ie/ health_information/nprs/nprs_reports/Perinatal_Statistics_Report_2010.pdf. Accessed 2 September 2013.

19. Jun Zhang M, Kai F, Yu P: What's the relative risk? JAMA 1998, 280(19):1690-1691. doi:10.1001/jama.280.19.1690.

20. Mozurkewich E, Chilimigras J, Koepke E, Keeton K, King VJ: Indications for induction of labour: a best-evidence review. BJOG 2009, 116(5):626-636.

21. Anim-Somuah M, Smyth RM, Jones L: Epidural versus non-epidural or no analgesia in labour. Cochrane Database Syst Rev 2011, 12:CD000331.

22. Wood S, Cooper S, Ross S: Does induction of labour increase the risk of caesarean section? A systematic review and meta-analysis of trials in women with intact membranes. BJOG 2013. doi:10.1111/1471-0528.12328.

23. Lutomski JE, Morrison JJ, Lydon-Rochelle MT: Regional variation in obstetrical intervention for hospital birth in the Republic of Ireland, 2005-2009. BMC Pregnancy Childbirth 2012, 12(123). doi:10.1186/1471-2393-1112-1123.

24. Joseph KS, Dodds $L$, Allen AC, et al: Socioeconomic status and receipt of obstetric services in Canada. Obstet Gynecol 2006, 107(3):641-650.

25. Movas TZ, Wells E, Mongoven A, Grigorescu V: Does medical insurance type (private vs public) influence the physician's decision to perform Caesarean delivery? J Med Ethics 2012, 38:470-473.

26. Boutsikou T: Malamitsi-Puchner. Caesarean Sect 2011, 100(12):1518-1522.

27. Groom KM, Paterson-Brown S, Fisk NM: Temporal and geographical variation in UK obstetricians' personal preference regarding mode of delivery. Eur J Obstet Gynecol Reprod Biol 2002, 100(2):185-188.

28. Fuglenes D, Kristiansen IS: Obstetrician's choice of cesarean delivery in ambiguous cases: is it influenced by risk attitude or fear or complaints and litigation? Am J Obstet Gynecol 2009, 200:48. e41-48.e48.

29. Brown HS: Lawsuit activity, defensive medicine, and small area variation: the case of cesarean sections revisited. Health Econ Policy Law 2007, 2(Pt 3):285-296.

30. Ryan K, Schnatz P, Greene J, Curry S: Change in cesarean section rate as a reflection of the present malpractice crisis. Conn Med 2005, 69(3):139-141.

31. Zwecker P, Azoulay L, Abenhaim HA: Effect of fear of litigation on obstetric care: a nationwide analysis on obstetric practice. Am J Perinatol 2011, 28(4):277-283.

32. Fuglenes $D$, Aas $E$, Botten $G$, Oian P, Kristiansen IS: Why do some pregnant women prefer cesarean? The influence of parity, delivery experiences, and fear. Am J Obstet Gynecol 2011, 205:45. e41-49.

33. Mazzoni A, Althabe F, Liu N, et al: Women's preference for caesarean section: a systematic review and meta-analysis of observational studies. BJOG 2011, 118(4):391-399.

34. Grobman WA, Lai Y, Landon MB, et al: The change in the rate of vaginal birth after caesarean section. Paediatr Perinat Epidemiol 2011, 25(1):37-43.

35. Pang MW, Law LW, Leung TY, Lai PY, La TK: Sociodemographic factors and pregnancy events associated with women who declined vaginal birth after cesarean section. Eur J Obstet Gynecol Reprod Biol 2008, 143(1):24-28.

36. Robson M: Can we reduce the caesarean section rate? Best Pract Res Clin Obstet Gynaecol 2001, 15(1):179-194.

37. Goetzinger KR, Macones GA: Operative vaginal delivery: current trends in obstetrics. Womens Health (Lond Engl) 2008, 4(3):281-290

38. O'Mahony F, Hofmeyr GJ, Menon V: Choice of instruments for assisted vaginal delivery. Cochrane Database Syst Rev 2010, 11:CD005455. doi:10.1002/14651858.CD005455.pub2.

39. Carroli G, Mignini L: Episiotomy for vaginal birth. Cochrane Database Syst Rev 2009, 21(1):CD000081.

40. ACOG Practice Bulletin No. 71: Episiotomy. Obstet Gynecol 2006, 107(4):957-962.

41. National Institute for Health and Clinical Excellence: Intrapartum care. London: UK: NICE clinical guideline 55; 2007.

42. Frankman EA, Wang L, Bunker CH, Lowder JL: Episiotomy in the United States: has anything changed? Am J Obstet Gynecol 2009, 200:573. e571-573.e577. 
43. Roberts CL, Algert CS, Raynes-Greenow C, Peat B, Henderson-Smart DJ: Delivery of singleton preterm infants in New South Wales, 1990-1997. Aust N Z Obstet Gynaecol 2003, 43(1):32-37.

44. McLachlan H, Forster D, Davey M, et al: Effects of continuity of care by a primary midwife (caseload midwifery) on caesarean section rates in women of low obstetric risk: the COSMOS randomised controlled trial. BJOG 2012, 119(12):1483-1492.

45. Yasmeen S, Romano PS, Schembri ME, Keyzer JM, Gilbert WM: Accuracy of obstetric diagnoses and procedures in hospital discharge data. Am J Obstet Gynecol 2006, 194(4):992-1001.

46. Hadfield RM, Lain SJ, Cameron CA, Bell JC, Morris JM, Roberts CL: The prevalence of maternal medical conditions during pregnancy and a validation of their reporting in hospital discharge data. Aust N Z J Obstet Gynaecol 2008, 48:78-82.

47. Kuklina EV, Whiteman MK, Hillis SD, et al: An enhanced method for identifying obstetric deliveries: implications for estimating maternal morbidity. Matern Child Health J 2008, 12(4):469-477.

48. Lutomski JE, Greene RA, Byrne BM: Severe maternal morbidity during childbirth hospitalisation: a comparative analysis between the Republic of Ireland and Australia. Eur J Obstet Gynecol Reprod Biol 2012, 163(2):148-153.

49. The Economic and Social Research Institute: Activity in acute public hospitals in Ireland. 2010. Annual Report Available: http://www.esri.ie/ health_information/latest_hipe_nprs_reports/2010_hipe_report/index.xml. Accessed 2 September 2013.

50. Khunpradit S, Tavender E, Lumbiganon P, Laopaiboon M, Wasiak J, Gruen RL: Non-clinical interventions for reducing unnecessary caesarean section. Cochrane Database Syst Rev 2011, 15(6):CD005528.

doi:10.1186/1471-2393-14-13

Cite this article as: Lutomski et al:: Private health care coverage and increased risk of obstetric intervention. BMC Pregnancy and Childbirth 2014 14:13

\section{Submit your next manuscript to BioMed Central and take full advantage of:}

- Convenient online submission

- Thorough peer review

- No space constraints or color figure charges

- Immediate publication on acceptance

- Inclusion in PubMed, CAS, Scopus and Google Scholar

- Research which is freely available for redistribution 